\title{
Numerical Investigation of the Air Flow Effects on Amorphous Alloy Ribbon Formation
}

\author{
Yongpeng Li, Cuiping Wang and Fengyin Wang \\ Energy Engineering Institute, Qingdao University, Qingdao 266071, China
}

\begin{abstract}
During the amorphous ribbon production process, the mechanisms that cause uneven thickness and herringbone on two surfaces of the ribbon are very complicated. The high velocity rotating roller causes periodic air eddies near the surface and air flow around the contact zone. The air flow might be the major reason that causes the non-uniformity thickness and the ripples. In this paper, a two-dimension model was developed to simulate the air flow eddies and a three-dimensional simulation was performed for the air flow field around the puddle zone. Simulation results show that the higher velocity of air flow around the puddle edges is closely related to thicker ribbon rim. The continuous air eddies along the roller surface and the air flow fluctuations along the roller width are the major reasons causing non-uniform convective heat transfer during ribbon solidification. The frequency of air eddy matches well with the nominal ripple frequency along the ribbon length, and the air flow fluctuation coincides with the herringbone wavelength along the ribbon width. The influences of the air flow on cooling, ribbon thickness, and herringbone phenomena are all discussed here.
\end{abstract}

\section{Introduction}

The amorphous alloy ribbon is a function material with the advantages of excellent magnetism, anti-corrosion, high mechanical strength and toughness, high electrical resistivity and conductivity. It has been widely used as the core material for electric motors, transformers, sensors, etc.

The rapid solidification process, shown in Fig. 1 [1], is a popular method for amorphous ribbon production nowadays, the melt Fe-based alloy liquid flows out of the crucible nozzle, impinges on the surface of the high speed rotating roller surface, spreads out rapidly forming thin ribbon. Similar approach has been presented in works [2]-[3]. The high pressure and high speed circulating cooling water inside the rotating copper roller takes the main solidification heat away. The width of the jet nozzle (B) and the gap $(\mathrm{G})$ between the nozzle and the roller surface are only about $0.3 \mathrm{~mm}$, as shown in Fig. 1(b). The alloy liquid solidifies into ribbon in a milliseconds to 0.5 second.

The heat transfer coefficient is a key factor to the solidification process, which has been studied by some researchers. Hui[4] calculated the cooling rates under different wheel velocities. The modeling results agree well with the experimental results except the region near the up-meniscus and down-meniscus. The simulation [3] showed that the heat transfer from the molten liquid to the air by convection is negligible, while the majority of heat $(\mathrm{Qw}$, approx. 2.7 MW) is conducted from the molten liquid to the roller, about $(1.8 \sim 2) * 10^{6} \mathrm{~W} / \mathrm{m}^{2} \mathrm{~K}[5]$.
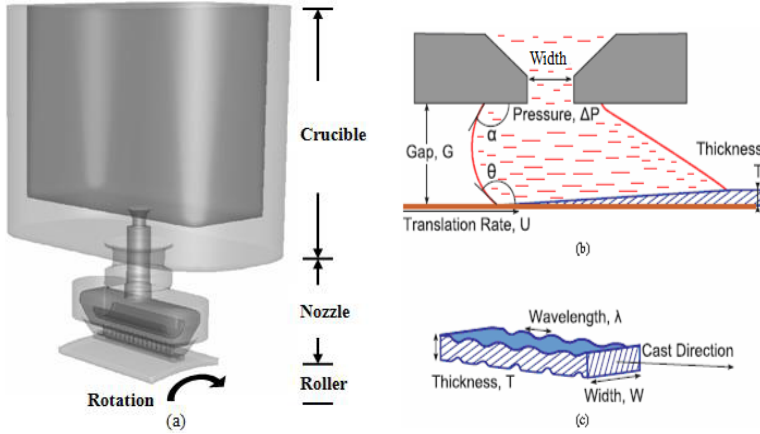

Figure 1. The ribbon production and the herringbone formation. (a) the amorphous ribbon production device; (b) the contact puddle zone; (c) ribbon cross section

So the size and shape of contact zone are very important to the cooling rate, which in turn influences the dendritic crystal growth and ripple wavelength formation [6]. Fig. 1(c) shows the ripple or herringbone formed on both ribbon surfaces during the solidification process. The pattern of ripple or herringbone is $\lambda f_{\lambda}=U$ [1]. The ripple or herringbone is desired for ribbon used as electrical resistivity and conductivity material because it reduces the energy lose when the electric motor no load working. Fig. 2 shows the ribbon produced by YUNLU Ltd. The Herringbone on the wheel-side is shorter in wavelength and shallower than those on the air-side. The study conducted [7] showed that no ribbon was formed under vacuum. So the ripple is clearly related to the air 
flow. The ripple width along the rotating direction is about $1 \mathrm{~mm}$ in the ribbon center and $2 \sim 3 \mathrm{~mm}$ near the edge.
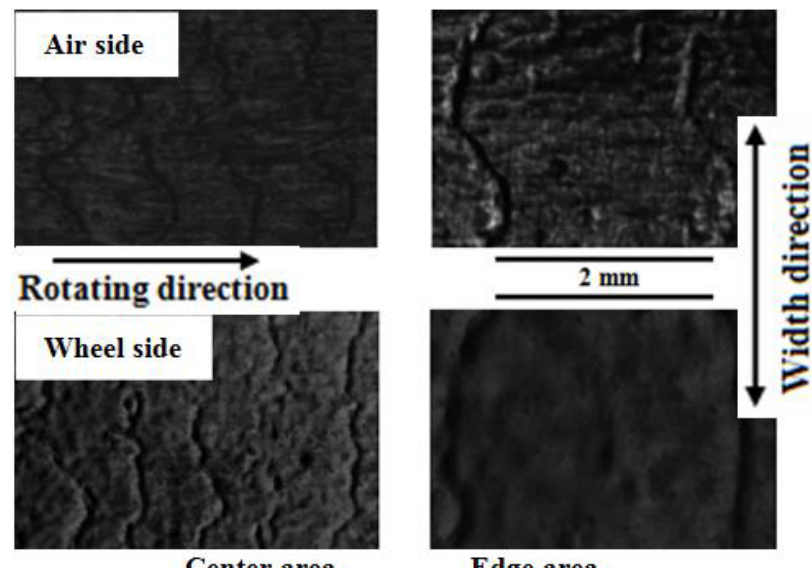

Center area

Edge area

Figure 2. Herringbone on the wheel side and Ripple on the air side surface of ribbon

The other distinct feature is the ribbon thickness. Previous studies show the thickness is related with the nozzle-wheel gap [8], wheel speed [2], [4], liquid viscosity [9], and thermal conductivity [5]. The thickness along the ribbon width is also uneven, which is thicker in the center and edge zones, as shown in Fig. 3. For the ribbon produced by Yunlu here, the variation in ribbon thickness is about $2 \sim 3 \mu \mathrm{m}$.

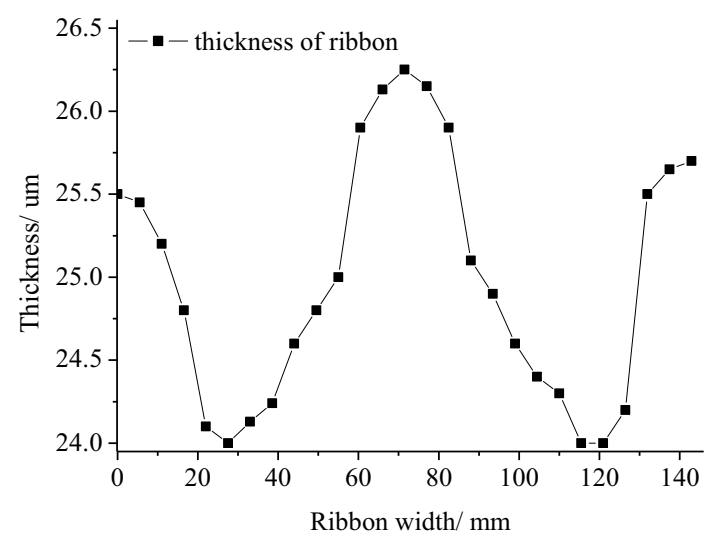

Figure 3. The ribbon thickness variation along the width.

The air flow over the roller played a key role, like the turbulence flow around a two-dimensional hump[10] and to fluctuated cool the alloy liquid. The nozzle effect and geometry are also the important factors[11]-[12]. In this paper, numerical simulation of air flow around the contact zone was carried out, including the air flow field over the rotating roller, the flow air scouring the contact zone, and the air flow around the nozzle. The influences of air flow on the convective heat transfer, ripple formation, and ripple thickness were discussed. The conductive heat transfer to the copper roller was regarded as uniform and the solidification process is neglected in this paper.

\section{Numerical simulation models}

The model developed in this paper is based on the rapid cooling device of the amorphous ribbon production line in Qingdao Yunlu New Energy Technology Co., Ltd. The study focuses on the rapid solidification area, including the nozzle and slot, the contact zone, the wheel-nozzle gap, and the rotating roller surface. For the ribbon width and length are all larger several degrees than the nozzle and puddle zone, a two-dimensional model was developed to simulate and focus on the shape of the molten puddle under the nozzle and the air flow regime along the roller surface with the roller swirling. Based on the inlet and outlet parameters obtained in this 2D simulation, setting the corresponding parameter values for a simplified $3 \mathrm{D}$ model, then the air flow in the gap and the entrainment and turbulent of flow around air was simulated three dimensional.

\subsection{Two-dimensional simulation of the molten puddle shape}

Fig. 4 shows the two-dimensional model developed for the molten puddle zone. The molten liquid flows out of the vertical nozzle slot $(0.3 \mathrm{~mm}$ in width), spreads on roller surface forming thin layer due to the rotating roller drag force. The data from YUNLU Co. were used as the boundary conditions for all simulations, which were listed in Table 1, including the roughness of the aluminum oxynitride refractory and the roller copper surfaces, the mean liquid velocity of the nozzle inlet, the dynamic pressure outside the contact zone, and the velocity of the roller surface. The main liquid iron physical properties at $1300^{\circ} \mathrm{C}$ used in all simulations were also listed. The $k-\varepsilon$ turbulent model and VOF twophase flow model were adopted for both the air flow and molten iron liquid. Since the length of the contact surface is much longer than the gap and nozzle slot, the roller surface was treated as a flat plane.

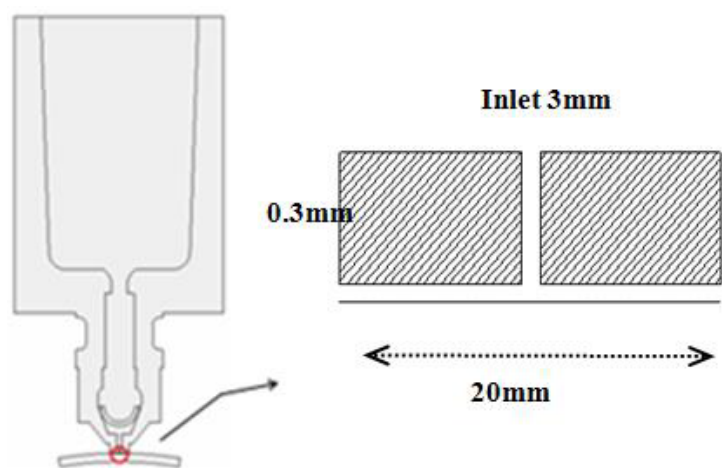

Figure 4. Two-dimensional model of the molten puddle zone

Table 1. The material physical properties in simulations

\begin{tabular}{cccccc}
\hline Material & $\rho /\left(\mathrm{kg} / \mathrm{m}^{3}\right)$ & $\mathrm{Cp} /(\mathrm{J} / \mathrm{kg} \cdot \mathrm{K})$ & viscosity $/(\mathrm{Pa} \cdot \mathrm{s})$ & $\lambda /(\mathrm{W} / \mathrm{m} \cdot \mathrm{K})$ & $\mathrm{roughness} /(\mathrm{um})$ \\
\hline liquid iron & 7000 & 462 & 0.00225 & 1 & 11 \\
\hline refractory & 2500 & 680 & $/$ & $/$ & 388 \\
\hline copper roller & 8978 & 381 & 0.8 & 38 \\
\hline
\end{tabular}




\subsection{Two-dimensional simulation of the air flow in the roller surface zone}

The diameter of the rotating roller is $800 \mathrm{~mm}$, several order of magnitudes larger than the nozzle and the gap between the roller and the nozzle. In this study, the region $30^{\circ}$ before and after the nozzle was studied, as shown in Fig. 5. The height of simulated zone is $25 \mathrm{~mm}$. The roller rotating velocity is $580 \mathrm{r} / \mathrm{min}$, which is the line speed of $24.3 \mathrm{~m} / \mathrm{s}$, the $k-\varepsilon$ turbulent model was also mainly used.

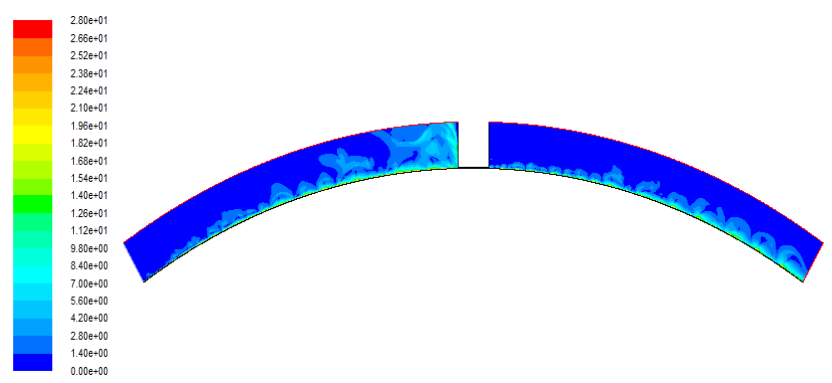

Figure 5. Two dimensional simulation zone and air flow velocity.

\subsection{Three dimensional model of the air flow around the nozzle}

A three-dimensional flow simulation was carried out for the analysis of air flow along the ribbon width. Fig. 6 shows the dimensions of the simulation region. The actual roller width is $165 \mathrm{~mm}$, the jet slot length is 142 $\mathrm{mm}$, shorter than the nozzle refractory solid, and shorter than the roller width, as shown in Fig. 6(a). The bottom is the roller surface, and the height of air flow zone is 25 $\mathrm{mm}$. The simulation was carried out using the Ansys Fluent 14.5 software. The inlet pressure (1.35bar) and outlet pressure (1bar) were used as boundary conditions for both two dimensional and three dimensional models. The rotating roller surface was treated as the moving-wall. The simulation was transient and the time step was set as variable in order to avoid the courant number exceeding the default limit.

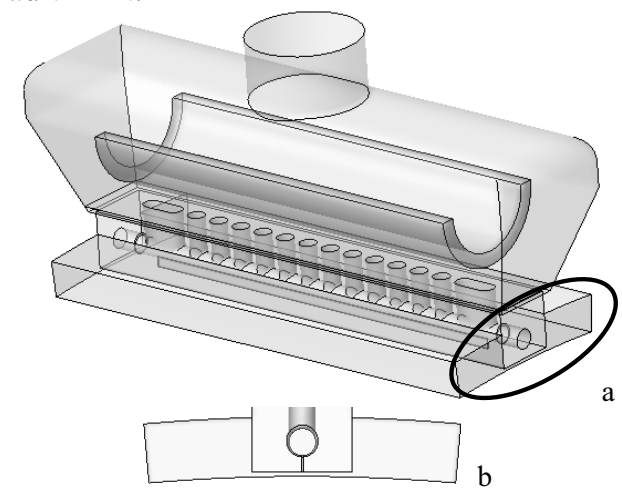

Figure 6. The three dimensional simulation region of air flow ( $b$ is the side view of simulation area).

\section{Results and discussion}

\subsection{The molten puddle shape}

Since the liquid iron is of weak wettability with the nozzle refractory materials, the iron liquid flows out without adhesion to the nozzle slot. As shown in Figure 7, the liquid iron was spread and layered due to the drag force of the high speed rotating roller surface[13]. Due to the fast roller rotation speed, very thin iron liquid layer (25um) was ultimately formed on the roller surface, by rapid cooling.

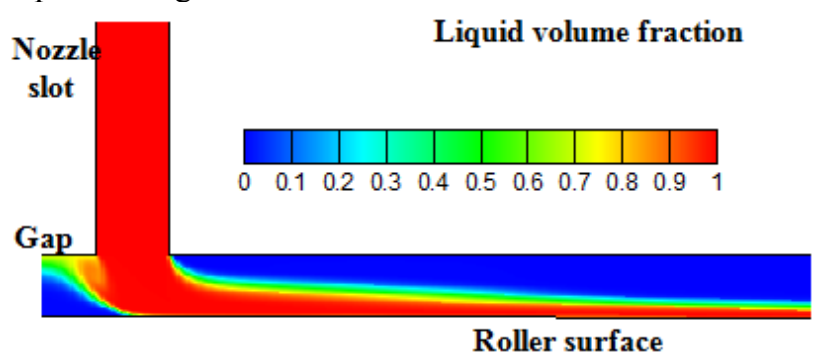

Figure 7. Shape of contact zone (molten puddle)

\subsection{Eddies on the roller surface}

Compared from the velocity vectors variation of two neighbored eddies shown in Fig. 7, the air flow has higher initial velocity tangential to the local roller surface, causing lower pressure between the roller and tangential air flow. When leaving the curve surface, the air flow slows down rapidly. Some air could be drawn back to form eddy flow, and some could blend with the follow up air to form another eddy. Some slower air flows into the back eddies, then the air is accumulated and the eddies become bigger and stronger till they hit the nozzle body. The air flow along with the rotating roller is blocked by the nozzle, forming large vortex, as shown in Fig. 8.

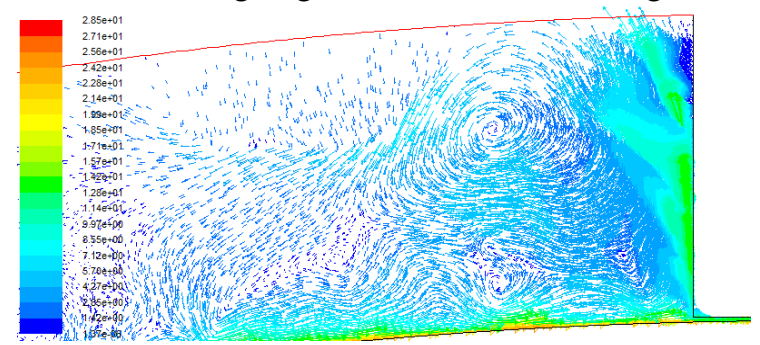

Figure 8. Eddies air flow in front of nozzle body.

Only a very thin layer of air very close to the roller flows into the gap under the nozzle. The air flow in gap is compressed and disturbed by the periodically reflected eddies, which causes air flow vibration and the subsequent periodic change in convective heat transfer between air and the molten iron liquid. The air in the gap after flowing around the molten puddle, ultimately flows out over the surface of the roller and the molten iron liquid, shown in Fig.9. there are also serious eddies along the rotating roller surface. Because the quantity of air flow through the gap is small, the initially formed eddies are small, which were later enhanced due to the air entranced from the surrounding area. So the ribbon would pass through several air eddies after peeling off the roller. 


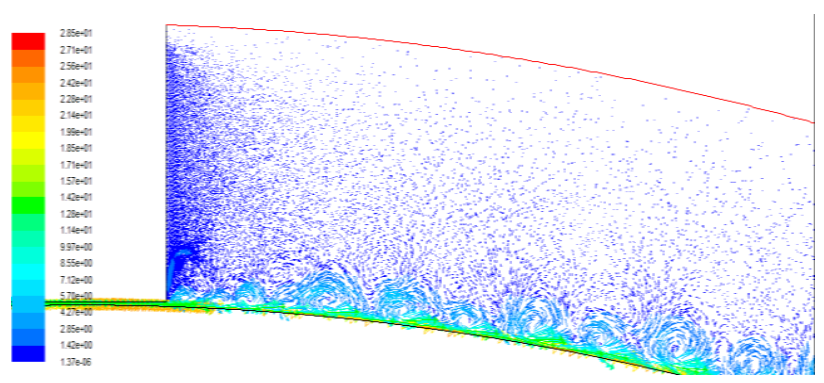

Figure 9. The eddy development of air flow at the back of nozzle.

The air eddies near the nozzle body could affect the cooling to the ribbon, cause periodic changes in the convective heat transfer and even the dynamic pressure on the ribbon surface. The eddy formed out of the solidification area exhibits the similar size to the ribbon ripple wavelength [1], [10], the formation mechanism of ripple on the air-side could be due to the periodic air flow eddies. When the upstream air flows in the gap approaching the liquid film, shown in Fig.10, the velocity is lower near center with regularly vibration; the amplitude of flow vibration is at least $3 \mathrm{~m} / \mathrm{s}$, which could contribute to the ripple formation from both solidification rate and air flow impact vibration.

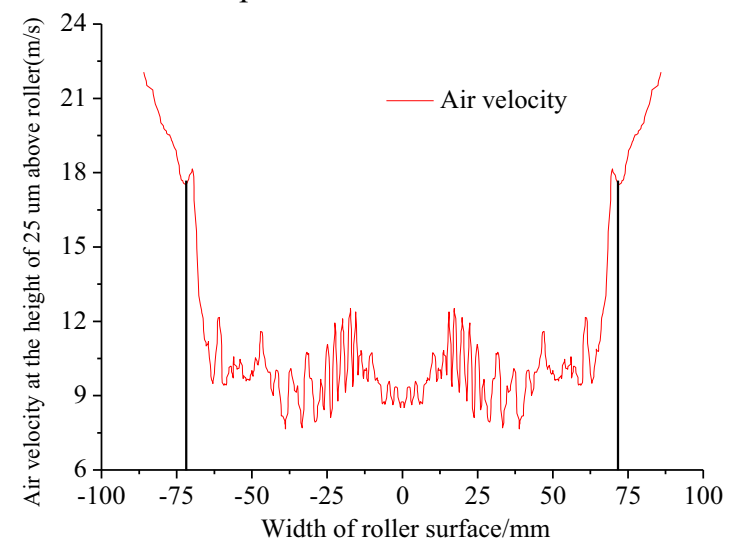

Figure 10. The air velocity along the roller width at the front of molten puddle (to wheel side of ribbon).

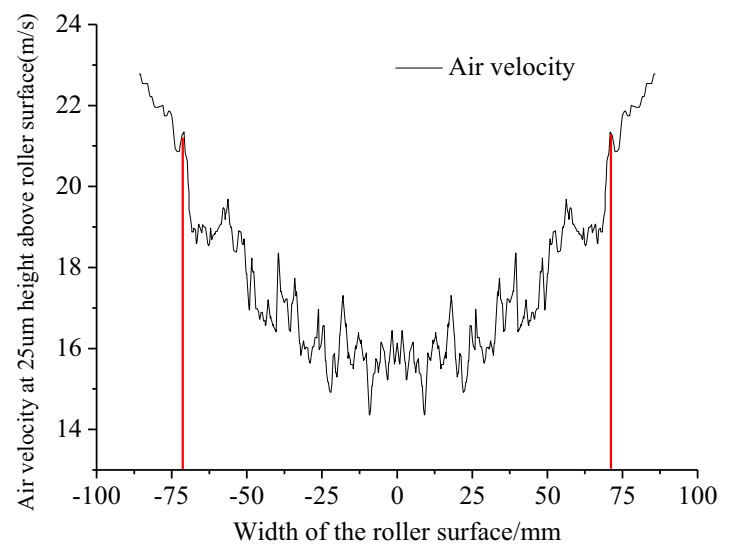

Figure 11. The air velocity along the roller width at the back of molten puddle (to air side of ribbon).

Fig. 11 shows the air velocity on the line of $1 \mathrm{~mm}$ downstream of the liquid film. The liquid is directly to be the air-side of the ribbon. The wavelength judged from the curve is shorter in the center and become longer on both sides, which match the feature of ripple as shown in Fig.2. The herringbones formed on the wheel-side surface is about $1 \sim 3 \mathrm{~mm}$ in wavelength, similar to the velocity vibration frequency.

For the air flow at the back of liquid film, the velocity is also similarly symmetric in Fig. 11, which is higher in velocity and more severe in vibration at the center area, the velocity increases gradually to its peak value and reduces a bit to a new valley, then increases to the highest value near the edges. The air velocity on the ribbon side is always higher than $15 \mathrm{~m} / \mathrm{s}$, and the velocity on the wheel side is about $10 \mathrm{~m} / \mathrm{s}$. As a consequence, the wave length is clearer and matches the air-side ripple size, causing deeper herringbones on the air side surface.

As seen, the ripples on the two sides are different due to the difference in air flow field. On the wheel-side, although the conductive heat transfer on the roller copper surface is uniform and is the main source taking away the solidification heat, the periodic vibration of air flow and the dynamic pressure shock on the contact zone cause difference in heat transfer and thus formed herringbones. Since the solidification of wheel side liquid is faster, the ripple is shallow and compressed to form herringbones. On the air side, the mixture air and periodic eddies influence the ribbon solidification and cause wave ripple formation.

\section{Conclusions}

(1) The non-uniform air flow and the corresponding influences on convective heat transfer could be the major reason for the two common features observed during the ribbon production. The air flow is induced by the fast rotating roller, and the air flow velocity in the gap is very high with regular fluctuation.

(2) The uneven ribbon thickness along the width is influenced by the air flow velocity variation and the high velocity air flow around the contact zone edges.

(3) The wave ripples formation is related with the periodic vibration along the width and the air eddies distribution along the rotation direction. The wheel-side surface undergoes more rapid cooling and compress, causing shallow herringbones. The continuous air eddies in the front of the contact zone influence the cooling and solidification, causing deeper wave ripple lines.

\section{Acknowledgment}

The financial support was received from the Natural Science Foundation of Shandong Province (Project No.ZR2015EM004) and National Natural Science Foundation of China (Project No.51676102) . Thanks for the Taishan Scholars Construction Engineering of Shandong province.

\section{References}

1. BL Cox, PH Steen. J. Mater. Process. Tech. 213,1743-1752 (2013). 
2. DR Li, JH Zhuang, TC Liu, ZC Lu, SX Zhou, J. Mater. Process. Tech. 211, 1764-1767(2011).

3. M Sowjanya, TKK Reddy. J. Mater. Process. Tech. 214, 1861-1870(2014).

4. XD Hui, YS Yang, XM Chen, ZQ Hu, Sci. Technol. Adv. Mater. 2, 265-270(2001).

5. MBussmanna, J Mostaghimi, DW Kirk, JW Graydon., Int. J. Heat Mass Tran. 45, 39974010(2002).

6. C J. Byrne, A M. Kueck, S P. Baker, P H. Steen. Mat. Sci. Eng. A-Struct. 459, 172-181(2007).

7. R Seino, YC Sato. J. Alloy Comp. 586(2014),S150S152.
8. D Raybould, M Meola, R Bye, SK Das. Mat. Sci. Eng. A 241,191-201(1998).

9. L.A.Anestiev. Mat. Sci. Eng. A 110,131-138(1989).

10. Yakeno, S Kawai, T Nonomura, K.Fujii. Int. J. Heat Fluid Fl. 22,235 - 240(2015).

11. ZG Pei, CW Yu. J. Fluid Struct. 27(1), 121133(2011).

12. Y. Otobe, H. Kashimura, S. Matsuo, T. Setoguchi, H.-D. Kim. J. Fluid Struct. 24(2), 281-293(2008).

13. CW Chen and WS wang. App. Math. Model. 19,704712(1995). 